Instituto Internacional de Investigación y Desarrollo Tecnológico Educativo INDTEC, C.A.

DOI: https://doi.org/10.29394/Scientific.issn.2542-2987.2021.6.21.17.314-335

OAI-PMH: http://www.indteca.com/ojs/index.php/Revista Scientific/oai

Ensayo Original / Original Essay

\title{
Investigación-acción-participativa: alternativa metodológica para el estudio de las comunidades. La visión de Orlando Fals Borda
}

\author{
Autores: Luis Alberto Velásquez \\ Instituto Universitario de Tecnología del Mar, IUTEMAR \\ losagradoyloprofano.6@gmail.com \\ Boconó, Venezuela \\ https://orcid.org/0000-0002-9295-7568 \\ Sandra Yorkley Alvarado Mendoza \\ Ministerio del poder Popular para la Educación, MPPE \\ sandrayalvarado29@gmail.com \\ Boconó, Venezuela \\ https://orcid.org/0000-0002-9668-9310 \\ Virginia del Valle Barroeta Hidalgo \\ Ministerio del poder Popular para la Educación, MPPE \\ barroetavirginia@gmail.com \\ Boconó, Venezuela \\ https://orcid.org/0000-0003-3590-7844
}

\section{Resumen}

La influencia del positivismo en el estudio de las ciencias sociales logró la rigidez de la aplicación de método en cuanto al estudio de las comunidades. Pero ante la vigencia de la propuesta social de la teoría crítica, se alternó la utilización del método positivista. El estudio se centra en mostrar que existen otros métodos para el estudio de las comunidades. En este sentido, la Investigación-Acción-participativa sustentada por Anisur y Fals (1988); GurdiánFernández (2007); Herrera y López (2014), lo muestran como método alternativo que sugiere el compromiso social, ético y científico del investigador. Es importante señalar, que muchos autores han tachado la Investigación-Acción-Participativa (IAP) como método marxista, sin embargo y sin olvidar su origen, este método plantea abordar el estudio de las comunidades desde la interdisciplinariedad con criterios sociológicos, antropológicos, educativos, políticos, sin parcialidad alguna. En conclusión, la metodología investigación acción participativa tiene sus orígenes en la lucha social con pretensiones liberadoras y emancipadora, en una visión multipolar, integradora y sintagmática, propone consideraciones que lo hacen propio de Latinoamérica. En tal razón, la aplicación del método IAP es contextualizado a la realidad de los pueblos latinoamericanos, pero exportado al mundo y a otras disciplinas como la educación, administración, politología y antropología.

Palabras clave: metodología; investigación social; investigación participativa. Código de clasificación internacional: 6311.01 - Estudios de comunidad.

\section{Cómo citar este ensayo:}

Velásquez, L., Alvarado, S., \& Barroeta, V. (2021). Investigación-acción-participativa: alternativa metodológica para el estudio de las comunidades. La visión de Orlando Fals Borda. Revista Scientific, 6(21), 314-335, e-ISSN: 2542-2987. Recuperado de: https://doi.org/10.29394/Scientific.issn.2542-2987.2021.6.21.17.314-335

Fecha de Recepción: 14-01-2021
Fecha de Aceptación: 15-07-2021
Fecha de Publicación: 05-08-2021 
Instituto Internacional de Investigación y Desarrollo Tecnológico Educativo INDTEC, C.A.

DOI: https://doi.org/10.29394/Scientific.issn.2542-2987.2021.6.21.17.314-335

OAI-PMH: http://www.indteca.com/ojs/index.php/Revista Scientific/oai

Ensayo Original / Original Essay

\title{
Participatory-action-research: methodological alternative for the study of communities. Orlando Fals Borda's vision
}

\begin{abstract}
The influence of positivism in the study of the social sciences made the application of the method rigid as regards the study of communities. But before the validity of the social proposal of critical theory, the use of the positivist method was alternated. The study focuses on showing that there are other methods for studying communities. In this sense, the Participatory ActionResearch supported by Anisur and Fals (1988); Gurdián-Fernández (2007); Herrera and López (2014), show it as an alternative method that suggests the social, ethical and scientific commitment of the researcher. It is important to note that many authors have crossed out Participatory Action-Research (PAR) as a Marxist method, however, and without forgetting its origin, this method proposes approaching the study of communities from an interdisciplinary perspective with sociological, anthropological, educational, criteria. political, without any bias. In conclusion, the participatory action research methodology has its origins in the social struggle with liberating and emancipatory pretensions, in a multipolar, integrative and syntagmatic vision, it proposes considerations that make it typical of Latin America. For this reason, the application of the IAP method is contextualized to the reality of the Latin American peoples, but exported to the world and to other disciplines such as education, administration, political science and anthropology.
\end{abstract}

Keywords: methodology; social investigation; participatory research. International classification code: 6311.01 - Community studies.

\footnotetext{
How to cite this essay:

Velásquez, L., Alvarado, S., \& Barroeta, V. (2021). Participatory-action-research: methodological alternative for the study of communities. Orlando Fals Borda's vision. Revista Scientific, 6(21), 314-335, e-ISSN: 2542-2987. Recovered from: https://doi.org/10.29394/Scientific.issn.25422987.2021.6.21.17.314-335
}

Date Received:

14-01-2021
Date Acceptance:

15-07-2021
Date Publication: 05-08-2021 
Instituto Internacional de Investigación y Desarrollo Tecnológico Educativo INDTEC, C.A.

DOI: https://doi.org/10.29394/Scientific.issn.2542-2987.2021.6.21.17.314-335

OAI-PMH: http://www.indteca.com/ojs/index.php/Revista Scientific/oai

Ensayo Original / Original Essay

\section{Introducción}

La historia del pensamiento muestra que el hombre se encuentra en la constante búsqueda de la innovación. Así se observa en todas las etapas que ha superado, desde la etapa de la filosofía natural o presocrática hasta la época postindustrial o posmoderna. Fue en el inicio de la modernidad cuando las posiciones de cambio de pensadores como Francis Bacon (1561-1626); y Galileo Galilei (1564-1642), promovieron un nuevo método para hacer ciencia inspirado en el empirismo y resoluciones matemáticas, lo que trajo como consecuencia el desplazamiento de posiciones metafísicas y teológicas que regían las ciencias, dando paso a una cultura o paradigma basado en la mecánica, relegando del sentimiento del sujeto a un segundo plano. En concordancia con lo planteado, Gurdián-Fernández (2007a), expresa que:

Este proceso de matematización del mundo y la naturaleza, el desarrollo paralelo de la burguesía y el comercio facilitaron e invirtieron las relaciones tradicionales entre lo cualitativo vinculado hasta ese momento a lo material-natural-sensible de carácter "primero" y "positivo"- y lo cuantitativo - vinculado hasta ese momento a lo formalizable y abstracto, a una "naturaleza de segunda" (págs. 11-12).

De acuerdo con Gurdián-Fernández (2007b): explica que la matematización del mundo trajo como consecuencia la división de las perspectivas sobre la realidad, teniendo como la más importante lo cuantitativo por estar ligado a lo medible y materializado, relegando a una segunda instancia lo cualitativo, y se deduce que esta postura da inicio, a lo que en el siglo XIX se llamó positivismo.

Paralelamente, la dicotomía entre el idealismo y el realismo surgida en el siglo $\mathrm{XVI}$, trascendió hasta los problemas científicos del siglo $\mathrm{XX}, \mathrm{Y}$ profundizado con la comprobación y verificación de las ciencias por parte del Circulo de Viena en el año 1922 y la descripción del fenómeno social por parte de la Escuela de Frankfurt en 1924. En este sentido, Gurdián-Fernández 
Instituto Internacional de Investigación y Desarrollo Tecnológico Educativo INDTEC, C.A. DOI: https://doi.org/10.29394/Scientific.issn.2542-2987.2021.6.21.17.314-335

OAI-PMH: http://www.indteca.com/ojs/index.php/Revista Scientific/oai

Ensayo Original / Original Essay

(2007c), manifiesta que:

El énfasis de los neo-positivistas del Círculo de Viena se centró en: superar la pseudo-ciencia y la comprobación y verificación empírica de todas las afirmaciones. Muy poco del pensamiento filosófico y de las ciencias humanas quedó en pie, pues fue rechazado como pseudo-ciencia (pág. 28).

Estas prácticas fueron comunes en los paradigmas tanto positivista como interpretativo, y estos a su vez adoptaron métodos propios a su filosofía de las ciencias, como lo son el método cuantitativo y el método cualitativo, estableciendo una ruptura entre lo subjetivo y lo objetivo, afectando de esta manera la forma de aprehensión de la realidad, por parte del cognoscente al conocido.

Pero ante el abuso y las exageraciones de ambos métodos en la realidad investigada, surge un nuevo paradigma y con él, un nuevo método, originario del paradigma sociocrítico, fundamentado en el paradigma emergente: El Método Investigación-Acción-Participativa (IAP). En sí, este método significa el mayor grado de integración de criterios científicos y la resolución de problemas, porque expresa la tolerancia entre el pensamiento racional y el pragmático.

La aplicación de este método conlleva al investigador a captar la realidad desde una perspectiva integral, dinámica, compleja y bidireccional, aprovechando las bondades que le ofrece la combinación de ambos métodos; tradicionales y postmodernos. Presenta Martínez (2015a), ante lo comentado que:

El método de la Investigación-Acción, tan modesto en sus apariencias, esconde e implica una nueva visión del hombre y de la ciencia. Es una metodología de resistencia contra el ethos positivista, que considera el análisis científico inaplicable a asuntos relacionados con los valores, e incluye supuestos filosóficos sobre la naturaleza del hombre y sus relaciones con el mundo físico y social (pág. 221). 
Instituto Internacional de Investigación y Desarrollo Tecnológico Educativo INDTEC, C.A.

DOI: https://doi.org/10.29394/Scientific.issn.2542-2987.2021.6.21.17.314-335

OAI-PMH: http://www.indteca.com/ojs/index.php/Revista Scientific/oai

Ensayo Original / Original Essay

En ese marco, Martínez (2015b): considera que el método IAP tiene una nueva visión de la realidad del hombre, donde la visión positivista no es la rectora, sino la concepción integral del hombre y del mundo. El método aparta de su ejecución la posición objetiva y mecánica del positivismo. Ante esto, asume la descripción y resolución de la problemática del hombre y la comunidad. Es importante resaltar, que muchos autores han seleccionado en sus investigaciones el método: Investigación -Acción- Participativa, para realizar estudios tanto en el campo educativo y social. En esa misma línea, Martínez (2015c), afirma:

Sin embargo, la IA, en su medio siglo de existencia, ha tomado básicamente dos vertientes: una más bien sociológica desarrollada principalmente a partir de los trabajos de Kurt Lewin, Sol Tax y Fals Borda- y otra más específicamente educativa, inspirada en las ideas y prácticas de Paulo Freire, Hilda Taba, L. Stenhouse, John Elliott y otros. Ambas vertientes han sido ampliamente exitosas en sus aplicaciones (pág. 223).

En referencia al tema, Martínez (2015d): menciona dos líneas de aplicación en la Investigación-acción-participativa: la educativa y social o sociológica, ambas han sido exitosas. Esto se debe a que la metodología genera la reflexión y la práctica. La reflexión sirve para concientizar sobre la realidad y la práctica para solucionar los problemas que presentan la escuela, comunidad y la empresa. Como manifiesta Martínez (2015e): Kurt Lewin, fue el pionero de la Investigación-Acción quien propuso un enfoque producto del sincretismo empírico-analista con un modelo de acción social. Por otro lado, Sandín (2003a), menciona que Lewin definió la Investigación- Acción como:

Un proceso de peldaños en espiral, cada uno de los cuales se compone de planificación, acción y evaluación del resultado de la acción. El trabajo de Lewin se centraba en el estudio científico de las relaciones humanas, con una atención especial hacia el cambio de actitudes y los prejuicios y en la mejora de la calidad de estas relaciones como consecuencia de su propia investigación. Dos de las ideas cruciales de su obra fueron las 
Instituto Internacional de Investigación y Desarrollo Tecnológico Educativo INDTEC, C.A.

DOI: https://doi.org/10.29394/Scientific.issn.2542-2987.2021.6.21.17.314-335

OAI-PMH: http://www.indteca.com/ojs/index.php/Revista Scientific/oai

Ensayo Original / Original Essay

de decisión de grupo y compromiso con la mejora (pág. 85).

En este mismo orden de ideas, Sandín (2003b): explica la concepción Kurt Lewin, sobre la Investigación-acción como el proceso investigativo que se somete a un espiral interminable, y que cada nivel se repetirá en función de ir mejorando los problemas encontrados, es decir, que soluciona los problemas, pero que si surgen otros se irán en la medida que el grupo evalué constantemente la dinámica trasformadora. Tales mejoras no se logran sino existe la decisión de las personas que compone un grupo y seguido de un compromiso. Todo esto desde la visión de la Psicología social y experimental.

Al respecto, Martínez (2015f): también menciona al Dr. Fals Borda (1925-2008), oriundo de Barranquilla, Investigador colombiano que utilizó la sociología como disciplina para crear conciencia en los pueblos del poder de organización y desarrollo socio-comunitario para resolver sus problemas. Escribió entre 30 libros y 70 artículos de publicación nacional e internacional, en estos, plasmó la concepción de la realidad existencial de los colombianos. Construyó una serie de neologismos que marcaron su pensamiento. Acorde con esto, Herrera y López (2014a), escriben sobre su pensamiento:

Los temas tratados son también múltiples y podrían seguirse en términos de antagonismos teóricopolíticos: a la tradición académica del colonialismo intelectual le antepuso la endogénesis contextual; promovió la "sociología de la crisis" en oposición al funcionalismo norteamericano; a la división territorial en función de los intereses del capitalismo supo promover el Kaziyadu y discutir nuevas formas de ordenamiento territorial que respondieran a las tradiciones y saberes de los pueblos; frente a las teorías y prácticas del socialismo importado, transgénico y dogmático, supo promover un socialismo raizal y tropical; frente a la visión de una ciencia aséptica e indiferente [...] (pág. 9).

De acuerdo con lo antes citado por Herrera y López (2014b): el pensamiento de Flas Borda contiene una serie de posiciones antagónicas, 
Instituto Internacional de Investigación y Desarrollo Tecnológico Educativo INDTEC, C.A.

DOI: https://doi.org/10.29394/Scientific.issn.2542-2987.2021.6.21.17.314-335

OAI-PMH: http://www.indteca.com/ojs/index.php/Revista Scientific/oai

Ensayo Original / Original Essay

personalistas, individualistas y autonomistas, constantes en su discurso social,

generando neologismos propios del contexto científico-social. Se explica entonces, que el pensamiento falsbordiano se enmarcó en una dimensión político-social, donde alternó la gestión sociológica con el compromiso político a favor de los protagonistas de la miseria humana y social, de los que sufrieron el daño colateral del imperialismo, colonialismo y capitalismo salvaje.

El fin de esta alternabilidad se evidenció en la pragmática del método: investigación-acción-participativa. En concordancia con lo planteado, Ocampo (2009a), escribe en razón al estudio del método IAP de Fals Borda:

En la Década de los Setenta, Orlando Fals Borda se interesó por realizar estudios con el método de investigación acción participativa, que buscaba la investigación sociológica en las culturas populares, conocer sus necesidades sociales y promocionar una conciencia social para transformar la realidad con base en las necesidades sociales en los grupos más necesitados de la población. Estas investigaciones sociológicas las promovió a través de la Fundación "La Rosca", de la cual fue director entre los años 1970 y 1975. Del mismo modo en esa Década fundó la Editorial "Punta de Lanza" y la revista "Alternativa" en la Década de los Setenta, la cual volvió a editar en los años Noventa (pág. 18).

La afirmación anterior de Ocampo (2009b): demuestra que Fals Borda asumió la IAP como herramienta social para abordar las comunidades desasistidas con problemáticas de toda índole, pero a su vez tratar de crear conciencia social en la trasformación del entorno; es decir, el sociólogo colombiano tuvo una visión integral de la IAP que superó lo metodológico y convertirlo en una propuesta existencialista.

Por tal razón, Fals Borda se convirtió en el autor más referenciado en cuanto al método IAP, por no excluir ninguna razón metodológica; siempre que no altere su objetivo terminal: transformar el entorno en función de las necesidades sociales. Por esta razón el método IAP desde la perspectiva de Fals Borda se ha convertido en una alternativa metodológica para el estudio 
de las comunidades en muchas partes del mundo. En este sentido, es importante mencionar a Anisur y Fals (1988a), quienes manifiestan:

Los congresos mundiales más recientes de sociología, sociología rural, antropología, trabajo social y americanistas han incluido discusiones y foros sobre la IAP, con extraordinaria concurrencia. Muchos gobiernos han nombrado investigadores formados en la IAP y han permitido alguna experimentación interna al respecto. Agencias de la Organización de las Naciones Unidas han reconocido esta metodología como alternativa viable [...] (pág. 50).

Adicionalmente, Anisur y Fals (1988b): en la cita muestran la IAP como alternativa metodología que pueda superar el paternalismo, la dependencia y sea en realidad una nueva vía para organizar la comunidad y mediante encuentros con compromiso resolver los problemas. La IAP progresivamente fue acogida por muchos gobiernos como método en los estudios sociales, en especial en el estudio de comunidades rurales y urbanas. En cuanto a las siglas que en algunos casos generan confusión, Anisur y Fals (1988c), expresan lo siguiente:

IAP, la sigla de "Investigación Acción Participativa", se usa en la América Latina. PAR, o sea Participatory Action-Research, se ha adoptado no solo en los países de habla inglesa sino también en el norte y centro de Europa: pesquisa participante en el Brasil; ricerca partecipativa, enquêteparticipation, recherche-action, Pantizipative Aktionsforchungen otras partes del mundo. En nuestra opinión, no hay en estas denominaciones diferencias significativas; no las hay especialmente entre IAP e IP (Investigación Participativa). Pero es preferible, como en la IAP, especificar el componente de la Acción [...] (pág. 46).

En la aclaración de Anisur y Fals (1988d): propicia un acuerdo para unificar criterios sobre la denominación oficial del método, porque la intención de los encuentros y congresos mundiales fue hacer un método preciso, claro, fuerte, de fácil aplicación y fundamentado en criterios filosóficos, 
antropológicos, sociológicos y políticos. Con esta aclaratoria muchos investigadores asumieron la denominación IAP para diferenciarlo de otros métodos con base filosófica diferente. En base a lo planteado, es necesario aclarar la línea de procedimiento del método IAP. En conformidad con Anisur y Fals (1988e), expresan:

De ahí también nuestras diferencias con la vieja línea de procedimiento de la investigación-acción propuesta por Kurt Lewin en Estados Unidos con otros propósitos y valores, movimiento que, según parece, ha llegado a un punto muerto intelectual. Así mismo, señalamos nuestras divergencias de la limitada "intervención sociológica" de Alain Touraine y la "antropología de la acción" de Sol Tax y otros, escuelas que no pasan de la técnica del muy objetivo y algo distanciado observador participante (pág. 46).

Estos mismos autores, plantean la diferencia del procedimiento del método IAP, con relación a otras propuestas desde la psicología social, la sociología objetivista y la antropología estructuralista, impregnadas de positivismo proceden de manera objetivo, separando de la investigación al sujeto, distintamente lo hace la IAP, ya que involucra al sujeto como protagonista y como sentipensante.

Ante lo expuesto, el objetivo del ensayo es resaltar la alternabilidad del método IAP, como herramienta para el estudio de las comunidades, método pensado en la idea de Fals Borda, que sirva para el método objetivista del cientificismo y de las ciencias sociales radicales.

\section{Desarrollo}

\subsection{Consideración sobre el origen y unificación del método}

Existen varias consideraciones sobre la IAP en general. La primera es sobre el origen. Se aporta que el método Investigación- Acción-Participativa, se formó desde la contribución de muchos intelectuales en la década de los setenta reunidos en diferentes partes del mundo. Entre los intelectuales se 
Instituto Internacional de Investigación y Desarrollo Tecnológico Educativo INDTEC, C.A.

DOI: https://doi.org/10.29394/Scientific.issn.2542-2987.2021.6.21.17.314-335

OAI-PMH: http://www.indteca.com/ojs/index.php/Revista Scientific/oai

Ensayo Original / Original Essay

encuentra el Dr. Orlando Fals Borda, que insatisfecho y sin respuesta ante los

problemas sociales por parte del gobierno y la academia decidió tomar acciones para establecer una vía alterna que le ayudara a responder muchas interrogantes de índole social, científica y humana. En relación con lo planteado Fals (1999a):

El primero de una serie de puntos de inflexión, afectados por las invivibles situaciones que observábamos, ocurrió en 1970. Entendíamos que las crisis se producían por la expansión del capitalismo y por la modernización globalizante, fenómenos que estaban acabando con la textura cultural y biofísica de las ricas y diversificadas comunidades que conocíamos. Guardar silencio y hacernos los ciegos ante el colapso de valores y actitudes sobre la naturaleza y los seres humanos que creíamos positivas, era una tragedia que sufríamos como en carne propia (pág. 74).

Con base en lo expuesto, Fals (1999b): consideró tomar decisiones que lo encaminara a la formación de una propuesta metodológica que superada la influencia científica del capitalismo y basarse en el paradigma alternativo marxista en oposición férrea contra el capitalismo, que es considerado por este como esclavizador de los que no tienen nada.

Tal paradigma se nutre de la crítica a los modelos paradigmáticos y los referentes teóricos que fundamentan la ciencia y las posturas academicistas que alimentan la objetivación de las perspectivas humana que persigue la resolución de los problemas sociales. En contra del academicismo europeo e imperial se inscribe la perspectiva de Fals Borda con la idea de la sociología comprometida, que tiene principio político, enmarcado en la endogénesis; es decir, todo se puede solucionar con la participación de los miembros de la comunidad.

Sin embargo, en la medida que fue creciendo la idea del método, las discusiones y participaciones de los intelectuales fueron purificando la concepción del método. En este sentido. Al respecto, Fals (1999c), apunta: 
Instituto Internacional de Investigación y Desarrollo Tecnológico Educativo INDTEC, C.A. DOI: https://doi.org/10.29394/Scientific.issn.2542-2987.2021.6.21.17.314-335

OAI-PMH: http://www.indteca.com/ojs/index.php/Revista Scientific/oai

Ensayo Original / Original Essay

Al discurrir la década de los setenta, nos resultó cada vez más claro que la I(A)P necesitaba nuevos elementos conceptuales que guiaran nuestro trabajo. Queríamos ir más allá de los primeros e inseguros pasos que habíamos dado con la psicología social (Lewin), el marxismo (Lukacs), el anarquismo (Proudhon, Kropotkin), la fenomenología (Husserl, Ortega), y las teorías liberales de la participación (Rousseau, Owen, Mili). No nos pareció suficiente hablar sólo de acción o de participación. También sentimos la necesidad de continuar respetando la validez inmanente de la metodología crítica, aquella que dispone de una sola lógica para la investigación científica [...] (págs. 76-77).

La idea de Fals (1999d): y de los intelectuales que acompañaron el sueño del método, fue obtener un método propio sin ninguna influencia de ideas prefabricadas, que de una u otra manera hayan contribuido a sostener la sociedad actual. Se requería un método que conjugara la teoría y la práctica en el desarrollo de las comunidades latinoamericanas y otras que todavía sentían el rigor del positivismo y el capitalismo.

Luego de una larga, pero fructífera espera se obtuvo un método: Investigación-Acción-Participativa, definido por Fals (1999e): como "[...] una vivencia necesaria para progresar en democracia, como un complejo de actitudes y valores, y como un método de trabajo que dan sentido a la praxis en el terreno" (pág. 82). Por esta razón este método se convirtió en una alternativa metodológica para abordar las comunidades. Sobre el asunto, Fals (1999f), opina:

Al paso de estos veinte años, en el Congreso Mundial de 1997 ya hubo una opinión diferente. Colegas de prestigio consideraron que los valores que por regla general se consideran constitutivos del paradigma dominante (consistencia, simplicidad, cobertura, certeza, productividad) pueden enriquecerse con valores participativos como el altruismo, la sinceridad de propósitos, la confianza, la autonomía y la responsabilidad social. [...] En fin, el paradigma alterno que aquí se dibuja por sumatoria parece confirmar el trabajo anterior y actual de la I(A)P [...] (pág. 85). 
Instituto Internacional de Investigación y Desarrollo Tecnológico Educativo INDTEC, C.A.

DOI: https://doi.org/10.29394/Scientific.issn.2542-2987.2021.6.21.17.314-335

OAI-PMH: http://www.indteca.com/ojs/index.php/Revista Scientific/oai

Ensayo Original / Original Essay

La opinión de Fals (1999g): muestra que el método: InvestigaciónAcción-participativa fue tomando forma en la medida que las discusiones avanzaban en los encuentros mundiales, hasta llegar a la noción del método participativo como se conoce hoy, el método se convirtió en un recipiente de alteridad, alternabilidad y humanismo.

\subsection{Consideración filosófica del método}

La segunda consideración es la filosófica, en la que la InvestigaciónAcción-participativa se fundamenta en los principios de la escuela inglesa que promueve la visión participante del mundo, como lo mencionan Herrera y López (2014c), en:

El án-gulo filosófico, está la escuela inglesa con Peter Reason y Hillary Blackbourne, que hablan de la visión participante del mundo, ellos han elaborado esa idea que es bastante comprensiva y que por supuesto orienta. Es una escuela filosófica que va más allá de la escuela fenomenológica de Husserl, de la cual partimos. Ya con la filosofía de la cosmovisión participante nos afirma más todavía en lo que queremos hacer filosóficamente (pág. 41).

La escuela de la visión participante considera que el individuo tiene un compromiso interventor en el cosmos, su intervención en la realidad cosmogónica puede modificar las rarezas o malformaciones ideológicas y materiales. También se fundamenta de la Escuela inglesa de Sussex, donde su mayor representante es Robert Chambers (1802-1871), que propone la aplicación rápida de la investigación-acción para resolver problemas concretos a través del diagnóstico rápido participativo. Por su parte, Herrera y López (2014d), muestran la opinión de Fals Borda en entrevista realizada:

Por el otro lado, por la parte práctica, surge la escuela de la investigación acción, la escuela de Sussex en Inglaterra con Robert Chambers, es la aplicación rápida, fácil, facilista de la investigación acción, para resolver problemas concretos, de corto plazo, lo que llaman el Diagnóstico Rápido Participativo 
Instituto Internacional de Investigación y Desarrollo Tecnológico Educativo INDTEC, C.A. DOI: https://doi.org/10.29394/Scientific.issn.2542-2987.2021.6.21.17.314-335

OAI-PMH: http://www.indteca.com/ojs/index.php/Revista Scientific/oai

Ensayo Original / Original Essay

(DRP). Eso son acciones puntuales. Chambers estuvo en Cartagena en el 97 explicando, no es divergente, es convergente, pero da un aspecto más práctico, incluso fue el puente para que la IAP llegara al Banco Mundial, y el Banco Mundial tuvo que crear un grupo de trabajo interno de participación, para imponer sus reglas de participación popular a los convenios y contratos que hacía con los gobiernos (págs. 41-42).

Estos autores manifiestan que a través del diagnóstico rápido participativo se pueden resolver problemas concretos, por ejemplo, arreglar un jardín. Para llegar a solucionar el problema deben reunirse todos los vecinos que comparten el jardín y observar las condiciones su estado. Luego tomar las decisiones a través de un plan, el que deben cumplir a cabalidad. Partiendo de esta situación se deduce que el diagnóstico rápido participativo es la máxima expresión del pragmatismo social. Por tales razones filosóficas la investigación-Acción-Participativa se convierte en el método que trasforma la realidad en base a la práctica.

En la misma consideración filosófica se encuentra la Gnoseológica, que plantea integrar el conocimiento teórico, conocimiento práctico y el conocimiento directo en la Investigación-Acción-participativa. Tal propósito no fue una resolución lineal y clara, esta estuvo marcada por muchas discusiones y controversias sobre la conjunción de la teoría y la práctica. De la misma forma, Herrera y López (2014e), en la búsqueda de afianzar la InvestigaciónAcción-participativa en los principios gnoseológicos:

El problema de la relación entre el pensar y el ser -la sensación y lo físico- se resuelve por la observación de lo material que [...] incluye no sólo lo constatable de la naturaleza sino también las condiciones fundamentales, primarias, de la existencia humana. [...] El problema de la formación y reducción del conocimiento no se resuelve diferenciando los fenómenos de las cosas en sí, sino planteando la diferencia entre lo que es conocido y lo que todavía no se conoce. [...] El problema de la relación entre el pensar y el actuar se resuelve reconociendo 
una actividad real de las cosas a la cual solo se adviene por la práctica que, en este sentido es anterior a la reflexión [...] El problema de la relación entre la forma y el contenido se resuelve planteando la posibilidad de superar su indiferencia por la práctica [...] (pág. 215).

En el primer principio propuesto por Fals (1997), citador por Herrera y López (2014f): sobre el problema entre el pensar y el ser, esta postura supera la materialidad a secas, porque incluye y otorga ánimo y vivencia, que mediante una observación trascendente deja ver estado físico y sensacional de la realidad. En cuanto al segundo principio de la formación del conocimiento, Incluye este principio el discernimiento, la reflexión y el análisis del conociendo que surge de las diferencias entre los fenómenos y las cosas en su estado físico. En el tercer principio Fals Borda plantea el paso trascendental de los esquemas mentales y de pensamiento para iniciar el camino hacia lo práctico, de allí que la teoría no pueda superase en la práctica. En el cuarto y último principio, plantea una igualdad, un binomio entre la teoría y la práctica; la teoría se convierte en la luz que ilumina la práctica y la practica una prolongación de la teoría.

\subsection{Dimensiones del método Investigación-Acción-participativa.}

\subsubsection{Primera dimensión: El diagnostico}

Después de muchas experiencias de estudio, discusiones, planificaciones y de campo, muchos autores han propuesto que para iniciar un posible plan de ordenamiento del método Investigación-Acción-participativa e iniciar el proceso investigativo, la inserción en el terreno es el primer paso, pero no es solo ir, es llegar al lugar conocer su contexto en general, pero también, llegar a las personas y convérselos de ejercer la acción comunitaria. Para Herrera y López (2014g):

Fueron los profesionales (especialmente los científicos sociales, aunque se observaron casos entre los de las ciencias 
exactas y naturales) quienes se plantearon primero la necesidad de la inserción al proceso histórico en varios niveles, especialmente el local o comunal, como forma de romper moldes de explicación y acción inadecuados. [...] Para el efecto, algunos abandonamos los recintos universitarios o pusimos en cuarentena los marcos de referencia de la ciencia ortodoxa y parcelada transmitida por la universidad tradicional (la inspirada por Scheler y traída luego a nosotros, la especializada y departamentalizada en intereses creados académicos) (pág. 244).

Por lo antes expuesto, Herrera y López (2014h): considera a la inserción como la vía de conocimiento del entorno, es salir al terreno a ver, a diagnosticar hechos, problemas, reformular conceptos, concordar teoría y práctica, con el fin de trasformar la realidad. El investigador al insertarse debe utilizar el método histórico o de investigación histórica para buscar datos y documentales que le ayuden a tener una visión geohistórico y geopolítica de la región.

Luego de haber realizado un diagnóstico, se debe elegir temas adecuados a nuestra conciencia para priorizarlos. Al seleccionar los temas 0 problemas, seguidamente se debe elegir grupos de apoyo comprometidos, estas deben ser personas de diversos orígenes y preparación intelectual para contribuir al proceso de reflexión, análisis, síntesis y sistematización de las ideas, buscando la absolutización entre la teoría y la práctica que sirvan de referentes teóricos en futuras investigaciones. El grupo de apoyo debe tener en cuenta varias técnicas de inserción: a). La técnica de la participaciónintervención; b). La técnica de la activación, para revisar el problema seleccionado; y c). La técnica de recuperación crítica, cuando se llega a las comunidades a rescatar las costumbres y la cultura tradicional.

\subsubsection{Segunda dimensión: La acción}

Luego de la inserción del grupo de investigadores o militantes sociales 
y haber realizado el diagnosticó, seleccionó del problema y planificó las acciones, se prepara para la acción tomando en cuenta algunas técnicas de observación que allanaran el camino a la acción concreta y comprometida. Luego el investigador debe asumir el compromiso-acción, lo que le llevara a tomar una serie de decisiones de formas organizadas y planificadas. Con respecto a este, Fals-Borda (2009a), dice que:

El compromiso-acción es, esencialmente, una actitud personal del científico ante las realidades de la crisis social, económica y política en que se encuentra, lo que implica en su mente la convergencia de dos planos: el de la conciencia de los problemas que observa y el del conocimiento de la teoría y los conceptos aplicables a esos problemas (pág. 244).

Según Fals-Borda (2009b): el compromiso-acción surge de la conciencia del investigador sobre el problema comunitario, pero también del ejercicio de su profesión, en el que aplica conocimiento a la resolución de los problemas. Desde este punto de vista, el investigador debe tomar decisiones en función de la acción-trasformación entre las que se cuentan:

1. Seleccionar acciones en función del tema elegido.

2. Las posibilidades de creación y originalidad que se abre con sus decisiones sobre el problema investigado.

3. Determinación y funcionabilidad del grupo clave o de apoyo.

\subsubsection{Tercera dimensión: La sistematización y la devolución sistemática}

Para el beneficio de la Investigación-Acción-participativa, en cada etapa u orden de la acción se debe sistematizar, en función de fundamentar la credibilidad del método, luego los datos sistematizados se enmarcan en el camino de devolverlos a la comunidad. La devolución de los datos a la comunidad permite revisar los procesos e iniciar nuevamente el proceso de investigación con la finalidad de repasar el origen de los problemas sociales y planificar nuevas acciones para solucionarlos. 
Instituto Internacional de Investigación y Desarrollo Tecnológico Educativo INDTEC, C.A.

DOI: https://doi.org/10.29394/Scientific.issn.2542-2987.2021.6.21.17.314-335

OAI-PMH: http://www.indteca.com/ojs/index.php/Revista Scientific/oai

Ensayo Original / Original Essay

La sistematización debe ser organizada, ordenada, concisa y precisa al

momento de la devolución a la comunidad, ya que de acuerdo con su presentación y difusión generada nuevos conocimientos. En concordancia con lo expresado, Herrera y López (2014i), muestra:

El principio de la "devolución sistemática" fue uno de los que más energías desató y más polémicas suscitó, quizás por tocar con elementos obvios que muchas organizaciones gremiales y políticas habían relegado a segun-do plano, no obstante su importancia. Porque asegurar la comprensión de lo que uno hace, dice o escribe, puede marcar la diferencia entre el éxito y el fracaso en un movimiento político o social (pág. 231).

Conforme a Fals (1997), citado por Herrera y López (2014j): para llegar al punto de la devolución sistemática se transitó un camino de disputas, sin embargo, se asumió desde lo común de muchas ciencias, construyéndose desde un sincretismo científico y unión de criterios. Expresar claramente el que hacer comunitario representa el éxito o el fracaso de años de estudio y trabajo, por tal razón le devolución sistemática de los resultados debe ser de suma importancia para los investigadores. Con base en la situación descrita por Herrera y López (2014k):

Finalmente, como ya se sugirió, para todos los proyectos y niveles se trató de adoptar un lenguaje directo, claro y sencillo para la comunicación de resultados. Esto obligó a revisar conceptos y definiciones, como quedó tam-bién explicado, y a combatir el estiramiento científico-académico y la verborragia especializada, lo cual llevó a diseñar formas nuevas de publicación y producción intelectual más abiertas y menos esotéricas y descrestadoras (pág. 233).

A este respecto se refiere el autor, para comunicar los resultados mediante la devolución sistemática, se debe hacer con un lenguaje popular, lejos de los enunciados academicistas que puedan presentar confusiones entre los miembros que reciben la información. 
Ensayo Original / Original Essay

\section{Conclusiones}

La modernidad marcó la división entre el objeto y el sujeto. En el desarrollo de la historia el método no escapó de esta polarización. El método positivista, inspirado en el empirismo y resoluciones matemáticas, imperó hasta el siglo XIX. A partir de la fecha, con el nacimiento de la fenomenología y la teoría crítica surgieron nuevos métodos de estudios en las ciencias sociales que hoy están vigentes. La Investigación-Acción-participativa es un método alternativo vigente, que en su concepción originaria pretende trasformar la realidad a través de la práctica superando las investigaciones netamente teóricas. El método IAP en la concepción latinoamericana plantea un problema político-social, pero en la aplicación sus gestores lo convirtieron en interdisciplinar, multidisciplinar e interdisciplinar.

La IAP en los diferentes congresos mundiales trató los problemas del nombre, el cual evolucionó desde la investigación-acción hasta los estudiosacción, pero el nombre de Investigación-Acción-participativa (IAP) prevaleció. En varios congresos, se planteó la Investigación-Acción-participativa Transformadora (IAPT), pero en si es lo mismo de Investigación-Acciónparticipativa, ya que esta conlleva naturalmente la trasformación. La misma tiene fundamentos filosóficos, epistemológicos y gnoseológicos enmarcados en el pragmatismo y la crítica social, pero su mayor fundamento está en la noción sentipensante que origina un neo humanismo en Latinoamérica, es decir, es la fusión entre el pragmatismo y el humanismo.

El método posee tres dimensiones: El diagnostico, que incluye la planificación para abordar los problemas sociales y comunitario; la dimensión de la acción. Donde se conjugan teoría y práctica en función de trasformar la realidad; dimensión de la sistematización y devolución de los resultados a los habitantes de la comunidad e investigadores de referencia. 


\section{Ensayo Original / Original Essay}

\section{Referencias}

Anisur, M., \& Fals, O. (1988,a,b,c,d,e). Romper el monopolio del conocimiento: situación actual y perspectivas de la InvestigaciónAcción participativa en el mundo. Análisis Político, (5), 46-55, ISSN: 0121-4705. Recuperado de:

https://revistas.unal.edu.co/index.php/anpol/article/view/74123

Fals-Borda, O. (2009a,b). La crisis, el compromiso y la ciencia. Bogotá, Colombia: Siglo del Hombre Editores; CLACSO.

Fals, O. (1999,a,b,c,d,e,f,g). Orígenes universales y retos actuales de la IAP. Análisis Político, (38), 73-90, ISSN: 0121-4705. Recuperado de: https://revistas.unal.edu.co/index.php/anpol/article/view/79283

Gurdián-Fernández, A. (2007a,b,c). El Paradigma Cualitativo en la Investigación Socio-Educativa. Colección: Investigación y Desarrollo Educativo Regional (IDER). ISBN: 978-9968-818-32-2. San José, Costa Rica: Coordinación Educativa y Cultural Centroamericana (CECC).

Herrera, N., \& López, L. (comps.). (2014a,b,c,d,e,f,g,h,i,j,k). Ciencia, Compromiso y Cambio Social: Orlando Fals Borda. $2^{a}$ edición, ISBN: 978-9974-0-1125-0. Montevideo, Uruguay: Editorial El Colectivo. Martínez, M. (2015,a,b,c,d,e,f). Comportamiento Humano: Nuevos métodos de Investigación. 2da edición (reimpresión), ISBN: 978-96824-5503-2. México: Trillas.

Ocampo, J. (2009a,b). El maestro Orlando Fals Borda sus ideas educativas y sociales para el cambio en la sociedad colombiana. Revista Historia de la Educación Latinoamericana, 12, 1341, e-ISSN: 0122-7238. Recuperado de:

https://www.redalyc.org/articulo.oa?id=86912021002

Sandín, M. (2003a,b). Investigación cualitativa en Educación: fundamentos y tradiciones. ISBN: 84-481-3779-5. Madrid, España: McGraw-Hill Interamericana. 


\section{Ensayo Original / Original Essay}

\section{Luis Alberto Velásquez}

e-mail: losagradoyloprofano.6@gmail.com

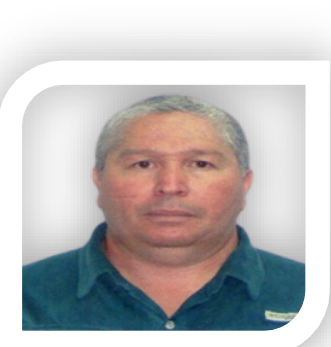

Nacido en Boconó, Venezuela, el 15 de abril del año 1970. Lcdo. en Filosofía por la Universidad Católica Santa Rosa (UCSAR). Lcdo. en Educación por la Universidad Católica "Cecilio Acosta" (UNICA) ; Especialista en Planificación educacional en la Universidad "Valle del Momboy" (UVM); Doctor en Educación del Instituto Pedagógico Rural "Gervasio Rubio"(IPRGR), Táchira; Docente del Ministerio del Poder Popular para la Educación, Venezuela; Profesor Invitado en Instituto Universitario de Tecnología del Mar (IUTEMAR) de la Fundación La Salle; Docente invitado en la Universidad de los Andes (ULA); Universidad Pedagógica Experimental Libertador (UPEL), Boconó, Trujillo, Venezuela; Docente de Postgrado y Pregrado eventual de la Universidad Pedagógica Experimental Libertador (UPEL); Investigador del PPI A-1. 


\section{Sandra Yorkley Alvarado Mendoza}

e-mail: sandrayalvarado29@gmail.com

Nacida en Boconó, Venezuela, el 29 de octubre del año

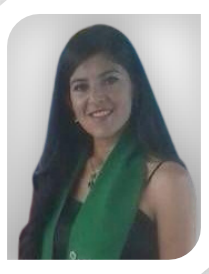
1987. Licenciada en educación por la Universidad Bolivariana de Venezuela (UBV); Magister en Recreación por la Universidad Pedagógica Experimental Libertador (UPEL); Docente del Ministerio del Poder Popular para la Educación (MPPE); Venezuela; Docente invitada en la Universidad Pedagógica Experimental Libertador (UPEL), Boconó, Trujillo, Venezuela. 


\section{Virginia del Valle Barroeta Hidalgo}

e-mail: barroetavirginia@gmail.com

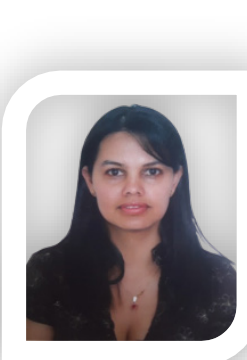

Nacida en Boconó, Venezuela, el 15 de septiembre del año 1984. Licda. en Educación Integral por la Universidad Pedagógica Experimental Libertador (UPEL); Magister en Recreación por la Universidad Pedagógica Experimental Libertador; Docente del Ministerio del Poder Popular para la Educación (MPPE), Venezuela; Docente invitada de pregrado y postgrado en la Universidad Pedagógica Experimental Libertador, Boconó, Trujillo, Venezuela.

El contenido de este manuscrito se difunde bajo una Licencia de Creative Commons ReconocimientoNoComercial-Compartirlgual 4.0 Internacional 